\title{
Adult Bone Marrow Stromal Cells in the Embryonic Brain: Engraftment, Migration, Differentiation, and Long-Term Survival
}

\author{
Guillermo Muñoz-Elias, Akiva J. Marcus, Thomas M. Coyne, Dale Woodbury, and Ira B. Black \\ Department of Neuroscience and Cell Biology and the Stem Cell Research Center, University of Medicine and Dentistry of New Jersey, Robert Wood \\ Johnson Medical School, Piscataway, New Jersey 08854-5635
}

\begin{abstract}
We recently differentiated adult rat and human bone marrow stromal cells (MSCs) into presumptive neurons in cell culture. To determine whether the MSCs assume neuronal functions in vivo, we now characterize for the first time engraftment, migration, phenotypic expression, and long-term survival after infusion into embryonic day 15.5 (E15.5) rat ventricles in utero. By E17.5, donor cells formed discrete spheres in periventricular germinal zones, suggesting preferential sites of engraftment. The cells expressed progenitor vimentin and nestin but not mature neuronal markers. By E19.5, a subset assumed elongated migratory morphologies apposed to radial nestin-positive fibers running through the cortical white matter and plate, suggesting migration along radial glial processes. Cells remaining in germinal zones extended long, vimentin-positive fibers into the parenchyma, suggesting that the MSCs generated both migratory neurons and guiding radial glia. Consistent with this suggestion, $>50 \%$ of cultured mouse MSCs expressed the neuroprecursor/radial glial protein RC2. From E19.5 to postnatal day 3, MSCs populated distant areas, including the neocortices, hippocampi, rostral migratory stream, and olfactory bulbs. Whereas donor cells confined to the subventricular zone continued to express nestin, cells in the neocortex and midbrain expressed mature neuronal markers. The donor cells survived for at least 2 months postnatally, the longest time examined. Confocal analysis revealed survival of thousands of cells per cubic millimeter in the frontal cortex and olfactory bulb at 1 month. In the cortex and bulb, 98.6 and $77.3 \%$ were NeuN (neuronal-specific nuclear protein) positive, respectively. Our observations suggest that transplanted adult MSCs differentiate in a regionally and temporally specific manner.
\end{abstract}

Key words: stem cells; embryonic brain; neurons; development; neurogenesis; differentiation

\section{Introduction}

Stem cells have been detected in multiple organs in the adult, leading to the emerging concept of stem cell plasticity. These cells exhibit the classical traits of self-renewal and multipotentiality. In addition to well known stem cells of the adult marrow lymphohematopoietic and stromal mesenchymal lineages (Prockop, 1997; Krause et al., 2001), stem cells have been provisionally identified in liver, muscle, CNS, and skin (Reynolds and Weiss, 1992; Morshead et al., 1994; Doetsch et al., 1999; Theise et al., 1999; Lee et al., 2000; Toma et al., 2001). Furthermore, differentiation is apparently not restricted to derivatives of the host tissue; adult stem cells can differentiate into progeny of other embryonic germ

Received Nov. 14, 2003; revised March 17, 2004; accepted March 21, 2004.

This work was supported by National Institutes of Health Grant P01 HD23315, New Jersey Commission on Science and Technology Grant 01-2042-007-23, New Jersey Commission on Spinal Cord Research Grant 01-3009-SCR-S-0, M. J. Fox Award 01.2002.003, and Albert Zofchak Fund Number 181-01R. We thank Drs. Emanuel DiCicco-Bloom, Cheryl Dreyfus, Noriko Kane-Goldsmith, and Junghup Suh for helpful discussions.

Correspondence should be addressed to Dr. Ira B. Black, Department of Neuroscience and Cell Biology and the Stem Cell Research Center, University of Medicine and Dentistry of New Jersey, Robert Wood Johnson Medical School, 675 Hoes Lane, Center for Advanced Biotechnology and Medicine 342, Piscataway, NJ 08854-5635. E-mail: black@cabm.rutgers.edu.

G. Muñoz-Elias's present address: Department of Neuroscience, University of California, San Francisco, San Francisco, CA 94143.

DOI:10.1523/JNEUROSCI.5060-03.2004

Copyright $\odot 2004$ Society for Neuroscience $\quad$ 0270-6474/04/244585-11\$15.00/0 layers. For example, neural stem cells (NSCs) can differentiate into blood (Bjornson et al., 1999), and myogenic elements (Galli et al., 2000) and hematopoietic cells have been differentiated into epithelial cells of the liver, lung, gastrointestinal tract, and skin (Krause et al., 2001). In another example, mature pancreatic exocrine-like cells have been differentiated into hepatocytes in the absence of mitosis, without passing through a stem cell stage, through a process of "transdifferentiation" (Shen et al., 2000).

We and others have recently differentiated adult rat and human bone marrow stromal cells (MSCs) into presumptive neurons in vitro (Sanchez-Ramos et al., 2000; Woodbury et al., 2000). The cells assumed characteristic neuronal forms and expressed a variety of neuron-specific genes and proteins, including neuronspecific enolase, tau, neurofilament $\mathrm{M}, \mathrm{NeuN}$ (neuronal-specific nuclear protein), $\beta$-III-tubulin, and synaptophysin (Woodbury et al., 2000, 2002).

Pioneering studies suggested that marrow cells also differentiate into neural cell types in vivo. Transplantation of cultured MSCs to mouse ventricles or striatum resulted in expression of astrocytic traits (Azizi et al., 1998; Kopen et al., 1999), and marrow cells have been used extensively in models of disease (Prockop, 1997; Lu et al., 2001; Sasaki et al., 2001). Systemic administration of whole marrow to mutant or irradiated mice leads to invasion of the brain and expression of neuronal markers 


\section{E16.5}
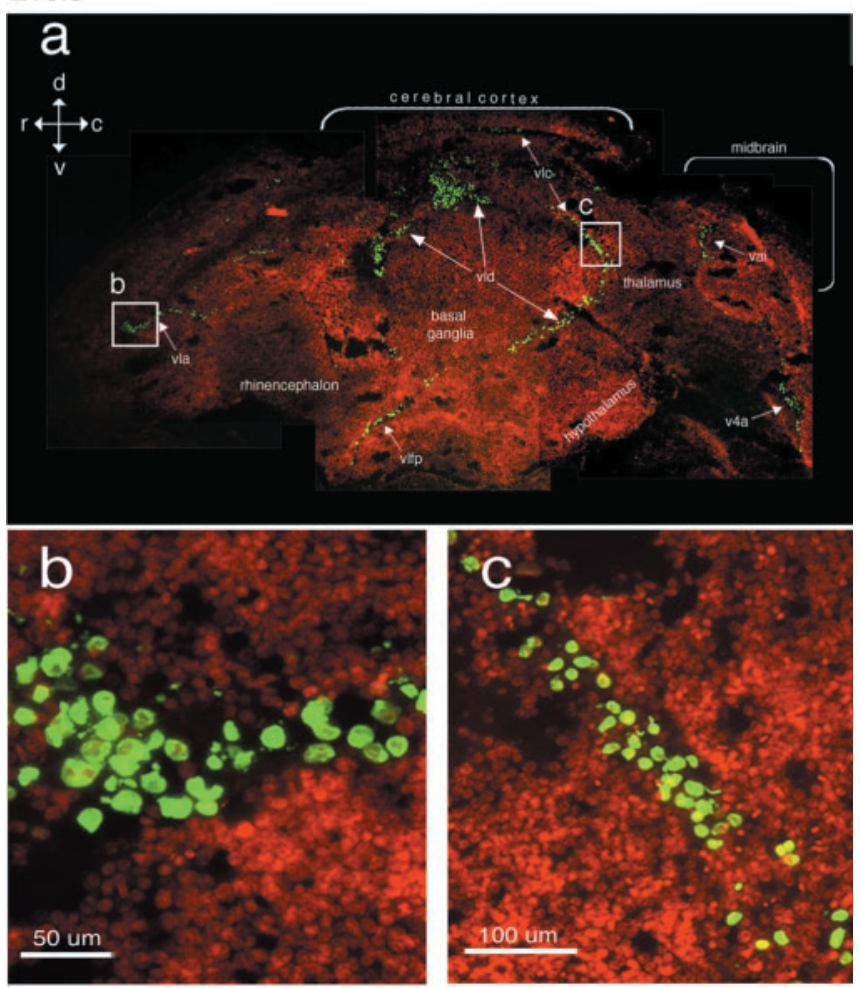

Figure 1. Infused MSCs diffuse widely throughout the embryonic ventricular system. $a$, Sagittal section immunostained for BrdU (green) and counterstained with propidium iodide (red) reveals extensive diffusion of donor MSCs throughout the ventricular system at E16.5 (24 hr after transplantation). BrdU-positive cells are evident in the anterior $(b)$ and central ( $c$ ) horns of the lateral ventricle, as well as the fourth ventricle and superior tectal aqueduct. $b$, Higher magnification of the box in $a$. c, Higher magnification of the area boxed in $a$ demonstrates that the majority of cells are confined to the ventricles and have not yet entered the parenchyma. $d$, Dorsal; r, rostral; v, ventral; c, caudal; vai, aqueduct, inferior tectal; vlc, lateral ventricle, central; vld, lateral ventricle, dorsal; vlfp, lateral ventricle, pallidal fork; v4a, fourth ventricle, anterior.

(Brazelton et al., 2000; Mezey et al., 2000). Collectively, the culture and live animal work supports the concept of stem cell plasticity. However, the systematic analysis of MSC developmental potential in normal rodent brain has yet to be examined.

Other studies questioned the concept of plasticity. One report failed to detect donor stem cell engraftment of the brain (Castro et al., 2002), and others observed cell fusion in vitro, potentially accounting for the apparent transdifferentiation (Terada et al., 2002; Ying et al., 2002). In contrast, a subsequent article confirmed in vivo transdifferentiation of marrow cells into buccal mucosa cells in the absence of cell fusion (Tran et al., 2003). Nevertheless, these apparently contradictory experimental results have raised important issues concerning the nature of stem cell plasticity.

Most generally, is the stem cell potential detected in culture expressed by the preponderance of MSCs in the brain of normal rodents in vivo? Is this potential exhibited by MSCs as opposed to whole marrow? More specifically, do MSCs undergo functionally critical developmental processes in vivo, including migration, definitive localization, engraftment, phenotypic expression, and long-term survival? Do MSCs migrate to multiple brain areas, consistent with multipotentiality? Do MSCs express neuroglial genes in a temporally and regionally specific manner, consistent with plastic responses to specific brain microenvironments?

To approach these questions and critically assess MSC plasticity in vivo, we introduced cells into the telencephalic ventricles of the neurogenetic embryo in utero. The cells assumed neuronal forms, expressed a variety of site-specific neuronal genes, and survived long term, for at least 2 months postnatally, the longest time tested. Our observations suggest that MSCs in the embryonic brain differentiate appropriately, exhibiting extensive plasticity in vivo.

\section{Materials and Methods}

Cell culture and bromodeoxyuridine-labeling. MSCs were isolated from adult female Sprague Dawley rats as described previously (Azizi et al., 1998; Woodbury et al., 2000, 2002). MSCs were maintained in DMEM$20 \%$ FBS. Bromodeoxyuridine (BrdU) at $10 \mu \mathrm{m}$ was added to the media to label S phase, dividing MSCs. Twenty-four hours before transplantation, the cultures were supplemented with $5 \mu \mathrm{g} / \mathrm{ml}$ basic fibroblast growth factor (bFGF) and $5 \mu \mathrm{M}$ BrdU. Cells were harvested with trypsin and pelleted from $10 \mathrm{ml}$ of DMEM twice to remove extracellular BrdU. After washing, the labeled MSCs were resuspended at 50,000 cells $/ \mu \mathrm{l}$ in $0.05 \%$ fast green-DMEM and iced until surgery. Aliquots of BrdUlabeled MSCs intended for surgery were plated and analyzed immunocytochemically for BrdU incorporation. More than $90 \%$ of the MSCs were BrdU positive $\left(\mathrm{BrdU}^{+}\right)$.

Transuterine intraventricular injection. Timed-pregnant rats, at embryonic day 15.5 (E15.5) served as hosts. Approximately 250 individual embryos were injected, and no subjects were excluded from analysis unless the injections failed, as indicated below. Animals were sedated by intraperitoneal injection of ketamine $(50 \mathrm{mg} / \mathrm{kg})$, xylazine $(2.6 \mathrm{mg} / \mathrm{kg})$, and acepromazine $(0.65 \mathrm{mg} / \mathrm{kg})$. A $3 \mathrm{~cm}$ ventral midline incision exposed the abdominal cavity, revealing the uterine horns and enclosed embryos. Guided by fiber optic transillumination, 2-3 $\mu$ l of MSC cell suspension $(100,000-150,00$ cells in total) were pressure injected into the lateral ventricles using a glass capillary pipette. Successful injections were evidenced by rapid diffusion of the fast green dye throughout the ventricular system. Embryos unsuccessfully injected were killed in utero by intraventricular infusion of $9 \%$ saline.

Removal and fixation of tissue. For prenatal time points, dams were killed, embryos were retrieved, and brains were microdissected. Brain tissue was immersion fixed in 4\% paraformaldehyde (PFA) for $24 \mathrm{hr}$ at $4^{\circ} \mathrm{C}$, rinsed three times with PBS, and then fixed for an additional $24 \mathrm{hr}$ in $30 \%$ sucrose- $4 \%$ PFA. Finally, tissue was stored in 30\% sucrose-PBS until cryosectioned. Postnatal animals were killed by an injection of pentobarbital $(0.5 \mathrm{ml}, 50 \mathrm{mg} / \mathrm{ml})$ and perfused with saline, followed by $4 \%$ PFA. Brains were removed and postfixed in $4 \%$ PFA for $24 \mathrm{hr}$ and subsequently stored in $30 \%$ sucrose-PBS until they were sectioned. All samples were sagittally cryosectioned at $16 \mu \mathrm{m}$ and processed immunocytochemically.

Immunohistochemistry and confocal analysis. Slides containing $16 \mu \mathrm{m}$ sections were rinsed extensively with PBS. Slides were placed in citric acid buffer solution, pH 6.0, microwaved until boiling, and allowed to cool slowly to ambient temperature. The microwave step was repeated three times for optimal antigen retrieval. For BrdU staining, the slides were incubated in $2 \mathrm{~N} \mathrm{HCl}$ at $37^{\circ} \mathrm{C}$ for $30 \mathrm{~min}$, followed by incubation in borate buffer, $\mathrm{pH}$ 8.4, for $20 \mathrm{~min}$. Tissues were blocked with 5\% donor goat serum for $45 \mathrm{~min}$. Sections were subsequently incubated for $24 \mathrm{hr}$ with primary antibodies: BrdU [mouse (ms), 1:50; Becton Dickinson, Mountain View, CA], BrdU (rat, 1:100; Accurate Chemicals, Westbury, NY), glial fibrillary acidic protein (GFAP) [rabbit (rb), 1:1000; Sigma, St. Louis, MO], $\beta$-III-tubulin (ms, 1:500; Chemicon, Temecula, CA), NeuN (ms, 1:250; Chemicon), MAP2ab (microtubule-associated protein) (monoclonal, 1:250), Calbindin (rb, 1:250; Chemicon), tyrosine hydroxylase (TH) (rb, 1:100; Chemicon), nestin (ms, 1:8; Developmental Studies Hybridoma Bank, University of Iowa, Iowa City, IA), RC2 (Developmental Studies Hybridoma Bank), and vimentin ( $\mathrm{ms}, 1: 20$; Developmental Studies Hybridoma Bank). After numerous washes, the sections were incubated with secondary antibodies: species-specific Alexa Fluor 594 or 488 were used (1:500; Molecular Probes, Eugene, OR). 

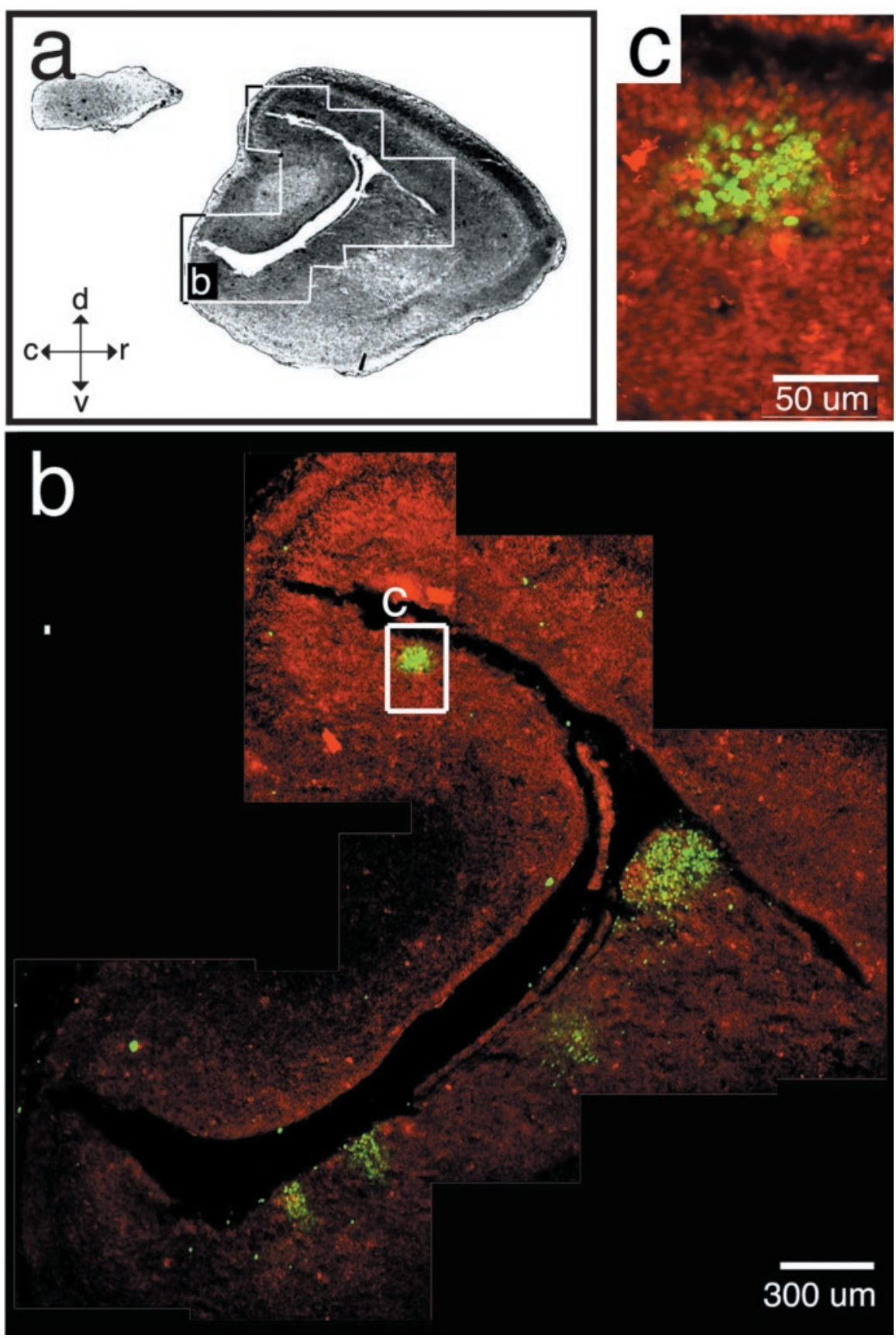

Figure 2. Transplanted MSCs enter the brain parenchyma as spheres. a, Overview of brain morphology at E17.5 highlighting the ventricular system. Outlined area is shown in detail in subsequent panels. $b$, Forty-eight hours after infusion (E17.5), BrdUlabeled MSCs (green) enter the brain predominantly as spherical cell clusters. c, High magnification of area boxed in $b$ demonstrating discrete BrdU labeling of intact MSCs interspersed with unlabeled endogenous cells. Propidium iodide was used as a counterstain (red). d, Dorsal; r, rostral; v, ventral; c, caudal.

Propidium iodide $(20 \mu \mathrm{g} / \mathrm{ml} \mathrm{H} 20)$ was used as a counter stain. Sections were coverslipped with Fluoromount G (Electron Microscopy Systems, Fort Washington, PA) and visualized with a Leitz (Wetzlar, Germany) Aristoplan Fluorescent microscope or a Zeiss (Nussloch, Germany) inverted confocal microscope. The monoclonal antibodies nestin (rat401), vimentin (40E-C), and RC2, developed by S. Hockfield (Yale University, New Haven, CT), A. Alvarez-Buylla (University of California, San Francisco, CA), and M. Yamamoto (University of Tsukuba, Tsukuba, Ibaraki, Japan), respectively, was obtained from the Developmental Studies Hybridoma Bank.

Morphometry. Tissue from three 1-month-old animals was used for cell counts for each area evaluated. Frozen sections, $16 \mu \mathrm{m}$ thick, were obtained in series; every third section was stained and analyzed. The number of sections counted per area ranged between 6 and 9. The total number of BrdU-labeled cells was calculated using the Abercrombie correction for double counting with respect to section thickness as described previously (Kramer et al., 1999). Donor BrdU-labeled cells were examined in the frontal cortex and olfactory bulb (OB). Cells in the cortex were counted in sagittal sections from the rostral-most extent of the lateral ventricle to the frontal pole. Donor cells in the $\mathrm{OB}$ were counted from the rostral-most extent of the $\mathrm{OB}$ to a limit of $500 \mu \mathrm{m}$ caudally. Random sampling of BrdU-positive cells from three areas of the frontal cortex and olfactory bulb were used to determine the percentage of donor cells positive for NeuN. For the frontal cortex, a minimum of 150 BrdU-positive cells was examined for each rat (three animals). For the $\mathrm{OB}$, a minimum of 100 cells was examined. All BrdU/NeuN-positive cells were confirmed using confocal analysis.

To estimate cell density, volume determination for the cortex and OB was calculated for each animal. For the frontal cortex, the length dimension was measured from the rostral extreme of the lateral ventricle to the frontal pole. Height was measured from the rostral extreme of the lateral ventricle to the dorsal border of the cortex. Depth was estimated from the $16 \mu \mathrm{m}$ sections. For the OB, length was measured from the rostral pole to $500 \mu \mathrm{m}$ caudally, and height was measured across the dorsoventral axis; depth was computed from the $16 \mu \mathrm{m}$ sections.

\section{Results}

\section{Ventricular MSCs invade the brain}

To determine whether adult rat bone MSCs assume neuronal functions in vivo, we characterized donor cells after transplantation. We assessed invasion, migration, and localization to definitive sites, phenotypic expression, and long-term survival after infusion of undifferentiated MSCs into E15.5 rat telencephalic ventricles in utero. MSCs were isolated and cultured as described previously (Azizi et al., 1998). Passage 17-21 MSCs were labeled with the DNA synthesis marker BrdU and were treated with bFGF before transplantation (see Materials and Methods). After this in vitro labeling protocol, $>90 \%$ of donor cells incorporated BrdU. One hundred thousand to 150,000 donor cells suspended in 2-3 $\mu$ l of DMEM were injected into each E15.5 recipient embryo lateral ventricle (for details, see Materials and Methods). In preliminary studies, we also used green fluorescent protein and cyan fluorescent protein as MSC labels but found that expression in vivo was variable. Consequently, we used BrdU in these studies, which favors detection of cells that divide no more than two times, without dilution of the label.

Briefly, intact uterine horns containing the embryos were exposed, and the embryonic ventricles were illuminated with highintensity fiber optic light. BrdU-labeled MSCs were infused into 
the visualized ventricles through the uterine wall. Successful transplantation was confirmed by rapid ventricular diffusion of the tracer fast green, which had been added to the MSC suspension. Surgical wounds were sutured, and the embryos were developed in utero until examination (for details, see Materials and Methods).

We initially characterized short-term survival and engraftment. During the first $24 \mathrm{hr}$ after transplantation, at E16.5, sheets of individual BrdU-labeled MSCs were apparent throughout the ventricular system, including the dorsal, central, and anterior horns of the lateral ventricle, superior tectal aqueduct, and fourth ventricle (Fig. 1). In contrast, $48 \mathrm{hr}$ after transplantation, at E17.5, discrete spherical clusters of engrafted MSCs were observed throughout periventricular germinal zones, such as the telencephalic ventricular (VZ) and subventricular (SVZ) zones (Fig. 2). In summary, MSCs infused into the lateral ventricles diffused freely throughout the ventricular system for $24 \mathrm{hr}$, engrafting into VZ/SVZ throughout the brain as discrete spherical clusters by $48 \mathrm{hr}$.

\section{Early phenotypic expression}

We next examined whether MSCs engrafted in the embryonic neuroepithelium expressed phenotypic traits associated with neuroprecursor cells. Brains were assayed immunocytochemically for colocalization of BrdU and either nestin or vimentin, intermediate filaments expressed by neuroprecursor or radial glia cells, respectively. (Lendahl et al., 1990; Noctor et al., 2002; Kriegstein and Gotz, 2003; Weissman et al., 2003).

Confocal analysis at E17.5 revealed colocalization of nuclear BrdU and cytoplasmic nestin (Fig. 3) in the forebrain VZ/SVZ. At E19.5, Z-series confocal reconstruction of BrdU/vimentin double-labeled sections revealed a subset of donor cells in the cerebellar peduncle/external germinal layer region extending long vimentin-positive fibers into the parenchyma (Fig. 4). These data suggest that MSCs express neuroprecursor and radial glial phenotypic traits in vivo. As expected, donor cells in germinal zones at E17.5 did not express the mature neuronal markers tau or MAP2 (data not shown). Consistent with this contention, parallel in vitro studies demonstrated that $>50 \%$ of cultured mouse MSCs express the neuroprecursor/radial glia protein RC2 (Fig. 4).

\section{Migration of MSCs}

The widespread distribution of transplanted MSCs raised the possibility that donor cells responded to endogenous guidance cues, engaging host mechanisms of cell migration. We investigated this possibility by double staining the E19.5 and E21.5 neocortical white matter and cerebral cortex for BrdU and for nestin, which is expressed in radial glial fibers in these regions (Noctor et al., 2002; Kriegstein and Gotz, 2003; Weissman et al., 2003). Analysis of Z-series confocal reconstructions revealed BrdU-positive MSCs with elongated, migratory nuclear morphologies closely apposed to radially oriented, nestin-positive fibers. The processes spanned the white matter and cortical plate at E19.5 and E21.5 (Fig. 5). Confocal analysis confirmed differential localization of BrdU-positive nuclei (Fig. 5) and nestin-positive radial glial
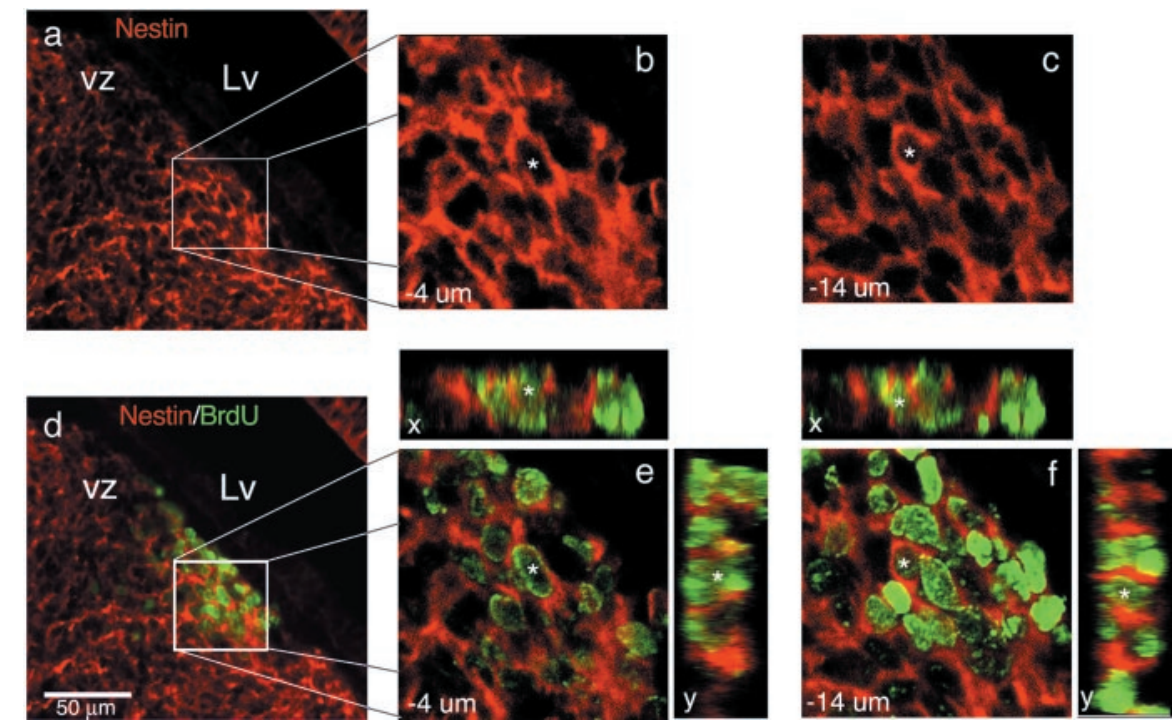

-14 um

Figure 3. Donor cells in the ventricular zone express nestin. $a$, Cells in the telencephalic ventricular zone (vz) express the colocalization of BrdU (green) and nestin reactivity, exemplified by the cell denoted with an asterisk. Analysis of XZ and $Y Z$ orthogonal planes confirms colocalization of BrdU and nestin signals. Lv, Lateral ventricle.

\section{E19.5}
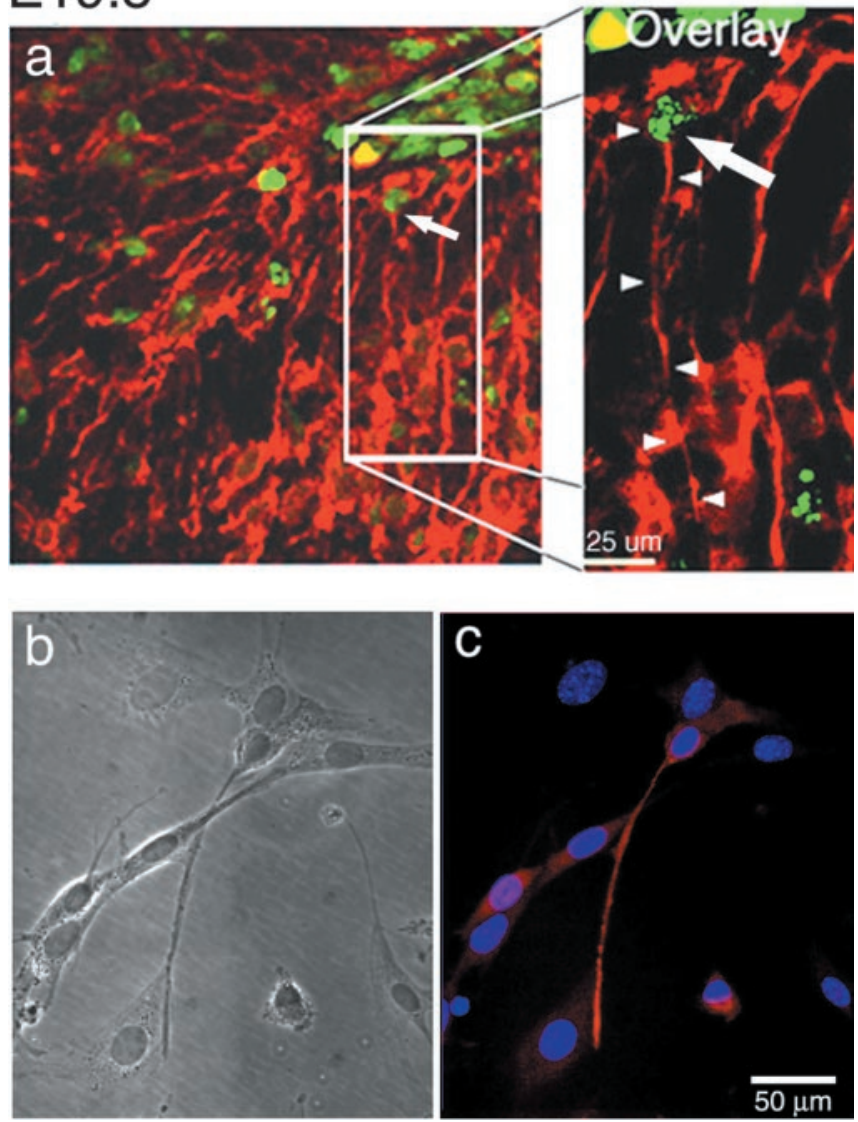

Figure 4. MSCs express the radial glial markers vimentin and RC2. a, Confocal Z-series reconstruction of the cerebellar peduncle/external germinal layer shows BrdU-labeled donor cells (green nuclei indicated by arrow) associated with vimentin reactivity (red). Higher magnification reveals a long vimentin-positive fiber (arrowheads) emanating from the BrdU-labeled donor cell (arrow). $b$, Phase contrast image shows murine MSCs growing in culture with elongated cell bodies. c, A subset of murine MSCs expresses the radial glial marker RC2 (red). Nucleiare stained with 4',6'-diamidino-2-phenylindole. 

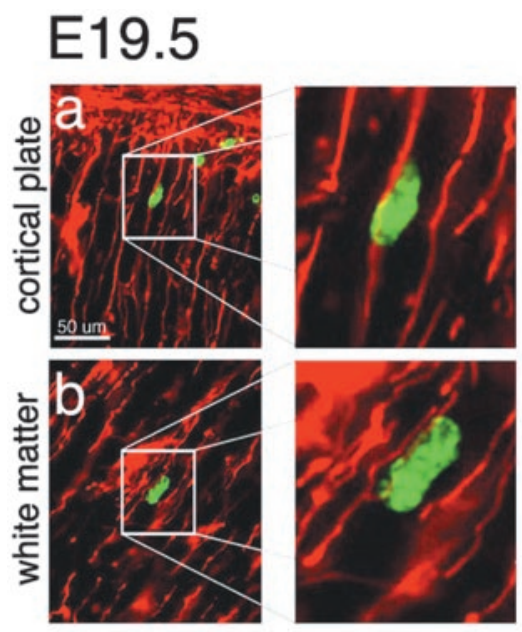

E21.5
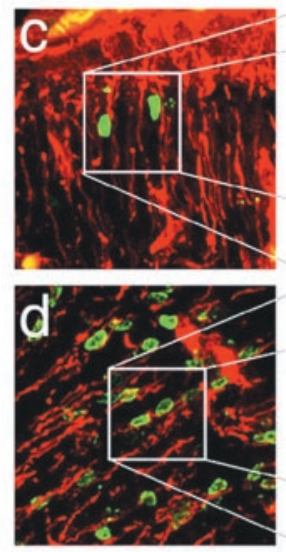

E19.5
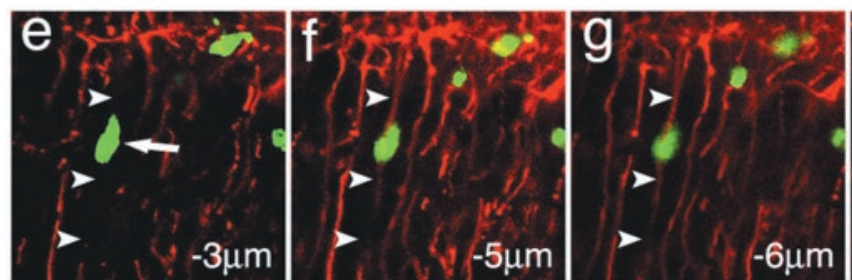

Figure 5. Donor MSCs are apposed to nestin fibers in the cortical plate and white matter. $a, b, Z$-Series confocal reconstructions reveal BrdU-labeled donor MSCs (green) with elongated, migratory nuclear morphologies closely apposed to radially oriented nestin-positive fibers (red) within the cortical plate $(a)$ and white matter $(b)$ at E19.5. High-power insets show that fibers do not emanate from BrdU-labeled cells but are juxtaposed. c, d, Z-Series confocal reconstructions indicate that putative migratory MSCs (green) are still evident at E21.5 in both the cortical plate $(c)$ and white matter $(d)$ in tight association with nestin-positive fibers (red). $e-h$, Confocal images of BrdU-labeled donor MSC (arrow) in the cortical plate at E19.5. Arrowheads indicate a nestinpositive fiber tightly associated with the donor MSC. The donor MSC is most readily visible at $-3 \mu \mathrm{m}(e)$, whereas the associated nestin-positive fiber is most clearly viewed at $-8 \mu \mathrm{m}(h)$, indicating that they do not comprise the same cell.

fibers (Fig. 5) in single optical sections 3, 5, 6, and $8 \mu \mathrm{m}$ below the section surface. Because germinal zone MSCs extended vimentin-positive fibers (Fig. 4), our observations suggest that MSCs generated both migratory neurons and guiding radial fibers.

\section{Longer-term distribution of MSCs}

We characterized the overall distribution of transplanted MSCs in recipient brains at E19.5, E21.5, and postnatal day 3 (P3). Widespread distribution of MSCs was detected in distant regions of the telencephalon, including the following: E19.5 neocortex and white matter (Fig. 6); E21.5 dorsal and ventral hippocampus, subventricular zone, white matter, and cortical plate (Fig. 6); and P3 subventricular zone, rostral migratory stream (RMS), and olfactory bulb (Fig. 6).

\section{Expression of immature neuronal markers in diverse areas}

The widespread migration of donor cells to distant CNS areas may expose different subpopulations of MSCs to different microenvironments. In turn, environmental signals may induce different MSC fates. Consequently, we examined area-specific MSC phenotypic expression using confocal analysis.

MSCs confined to the subventricular zone continued to express the neuroepithelial marker nestin at E19.5 and E21.5 (Fig. 7 ). In contrast, another subset of donor cells in the pons and basal ganglia exhibited astrocytic morphologies and expressed the astrocyte marker GFAP (Fig. 8).
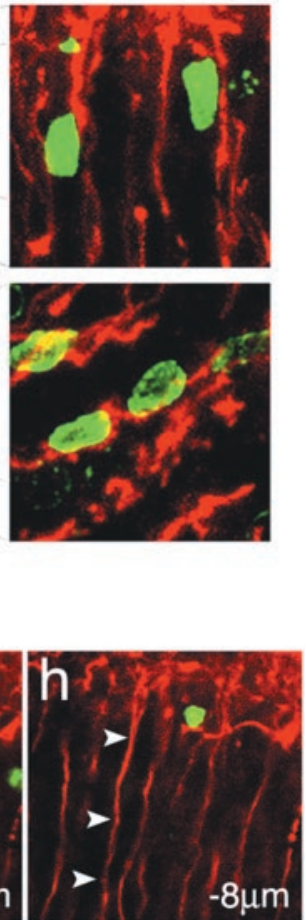

Four days after transplantation, MSCs in the midbrain exhibited multipolar neuronal morphologies and expressed the immature neuronal protein $\beta$-III-tubulin (Fig. 9), consistent with immature neuronal phenotypic expression.

\section{Maturation of phenotypic expression:} temporal and area specificity

To assess ongoing development, we examined E19.5 and E21.5 sections through the neocortex for the mature neuronal proteins tau and MAP2. MSCs with elongated nuclear morphologies in the white matter at E19.5 did not express tau, as indicated by rotating the $\mathrm{Z}$-series reconstruction $360^{\circ}$ (Fig. 10). In contrast, MSCs in cortical layers at E21.5 expressed mature neuronal tau and MAP2 (Fig. 10). BrdU/tau and BrdU/MAP2 cellular colocalization was determined confocally by analysis of Z-series reconstructions and single optical sections in corresponding $y z$ and $x z$ orthogonal planes. In summary, different subsets of MSCs expressed different gene products and morphologies in a temporal and area-specific manner, suggesting that MSCs respond to specific signals in different microenvironments.

\section{Expression of region-specific \\ phenotypes: calbindin and \\ tyrosine hydroxylase}

To determine whether MSC-derived neuronal subtypes were regionally specified, we examined the olfactory bulb as a prototype. The bulb was selected because we detected an extensive population of $\mathrm{NeuN}^{+}$donor cells in the periglomerular region at 1 and 2 months (see next section, Quantitative analysis of MSC distribution and survival) and because different gene products have been localized to distinct subpopulations of periglomerular cells (Halász et al., 1977, 1985). For example, the periglomerular layer contains calbindin- and $\mathrm{TH}$-immunoreactive neurons in distinct, non-overlapping subregions.

In fact, we detected calbindin expression in $\mathrm{BrdU}^{+}$MSCs within the external plexiform layer of the periglomerular region (Fig. 11), consistent with previous reports of the distribution of these neurons in the normal mature brain (Halász et al., 1985). Rotational analysis of $360^{\circ}$ around the $y$-axis definitively colocalized BrdU and calbindin (Fig. 11).

Conversely, TH was colocalized to a distinct $\mathrm{BrdU}^{+}$subpopulation in a separate subregion of the periglomerular region (Fig. 12), as described previously (Halász et al., 1985). In summary, these observations are consistent with the regional specification of differentiation of neuronal subtypes from the MSC donor population.

\section{Quantitative analysis of MSC distribution and survival}

To obtain a quantitative estimate of the distribution and survival of transplanted MSCs, we used unbiased stereology, using a modification of Abercrombie's method (see Materials and Methods) (Kramer et al., 1999). We examined multiple brain areas at 1 and 2 months postnatally, after transplantation of MSCs at E15.5. The 
donor cells were widely distributed, consistent with the embryonic pattern. At 1 and 2 months postpartum, abundant BrdU-positive cells were apparent in the following: olfactory bulb and rostral migratory stream; the frontal, parietal, and occipital cortices (predominantly in the upper laminas); the hippocampus and dentate gyrus; and the VZ and SVZ. MSCs were so densely packed in the SVZ (Figs. 2, 3 ) that it was often difficult to resolve individuals, and we used other areas to perform reliable morphometry. We chose the 1 month frontal cortex and olfactory bulb as representative areas for detailed analysis and scored multiple sections from each of three rats (Table 1). Abundant cells were apparent, although numbers varied from animal to animal (Table 1). In the frontal cortex, BrdU-positive cells varied from $118 \pm 22$ to $501 \pm 88$ per $16 \mu \mathrm{m}$ section. To obtain an estimate of donor cell number per unit volume, we counted cells in the area circumscribed by the rostral extreme of the ventricle to the frontal pole and by the dorsal extreme of the ventricle to the dorsal extent of the cortex. We summed the volume over the total number of sections counted for each rat (for details, see Materials and Methods). We calculated that the frontal cortices of the three individual rats contained 4792, 2152, and $1124 \mathrm{BrdU}^{+}$cells $/ \mathrm{mm}^{3}$, respectively, 1 month after transplantation.

In the 1 month olfactory bulb, MSCs varied from $49 \pm 9$ to $239 \pm 32$ cells per 16 $\mu \mathrm{m}$ section among individual animals (Table 1). To estimate the density of MSCs, we used an area circumscribed by the rostral extreme of the bulb to $500 \mu \mathrm{m}$ caudally and a height spanning the dorsoventral extent of the bulb. The depth was estimated from section thickness, as above. For the three rats, MSC density measured 10,864, 10,091, and 2229 cells/ $\mathrm{mm}^{3}$. Consequently, the MSCs displayed extensive long-term survival from the embryonic to the young adult host brain.

To determine whether the surviving MSCs exhibited neuronal traits, we exam-

Figure 6. Donor MSCs disperse to distant brain regions in embryonic and postnatal animals. E19.5, $a$, Subsets of donor MSCS (green) are found in distant CNS regions, such as the neocortex (ncx), as early as E19.5 (4 d after transplantation). E21.5, Donor cells integrate into the both the dorsal and ventral hippocampus. A population of MSCs remain in the subventricular zone. $P 3$, At the earliest postnatal time examined, subsets of MSCS are retained in the subventricular zone (a). Populations of MSCs are also detectable in the rostral migratory stream $(b)$ and in the olfactory bulb (c). In all images, nuclei are counterstained with propidium iodide (PI, red). ps, pial surface; Lv, lateral ventricle.

\section{E19.5}

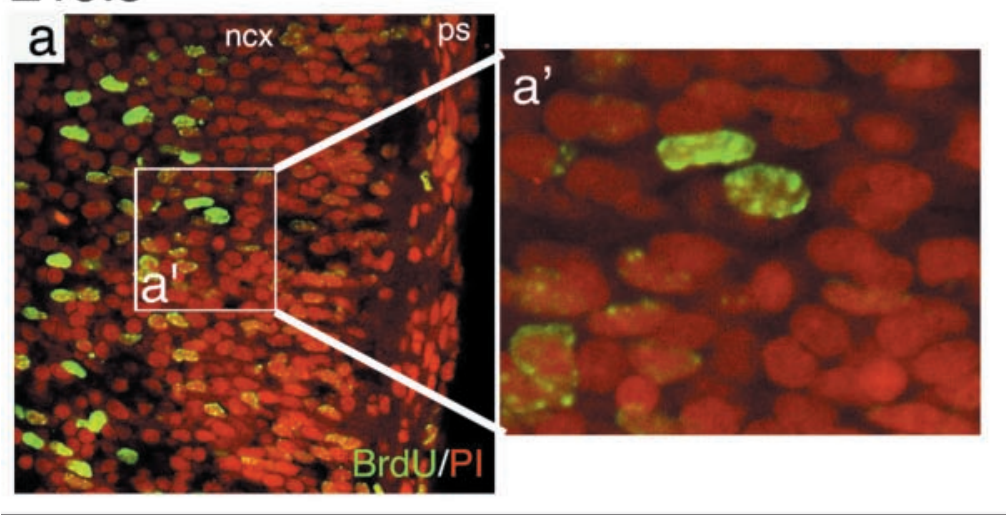

\section{E21.5}

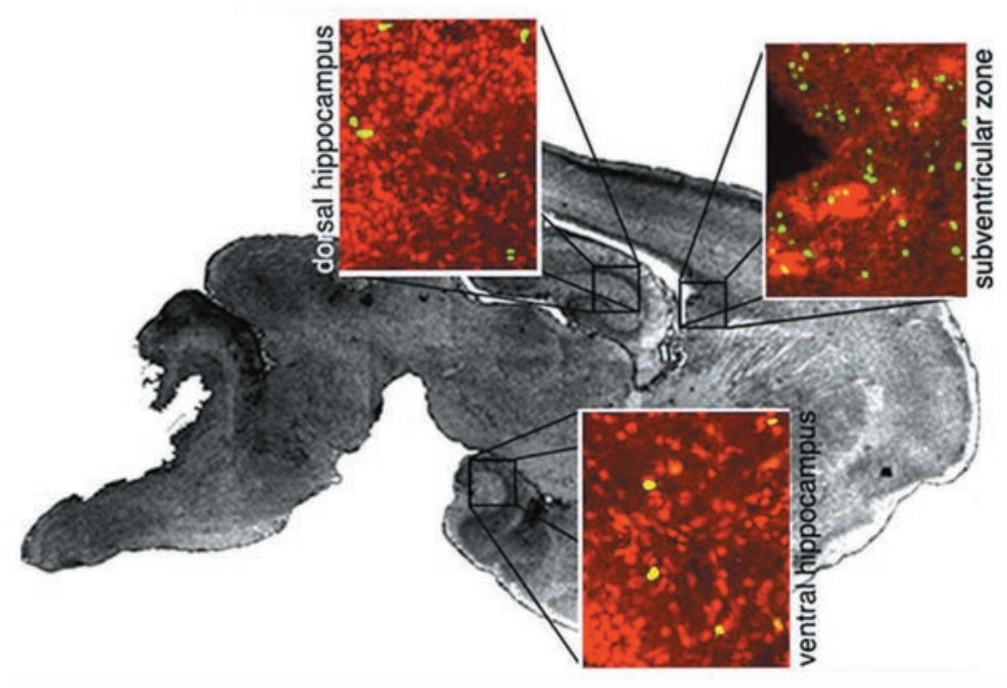

P3
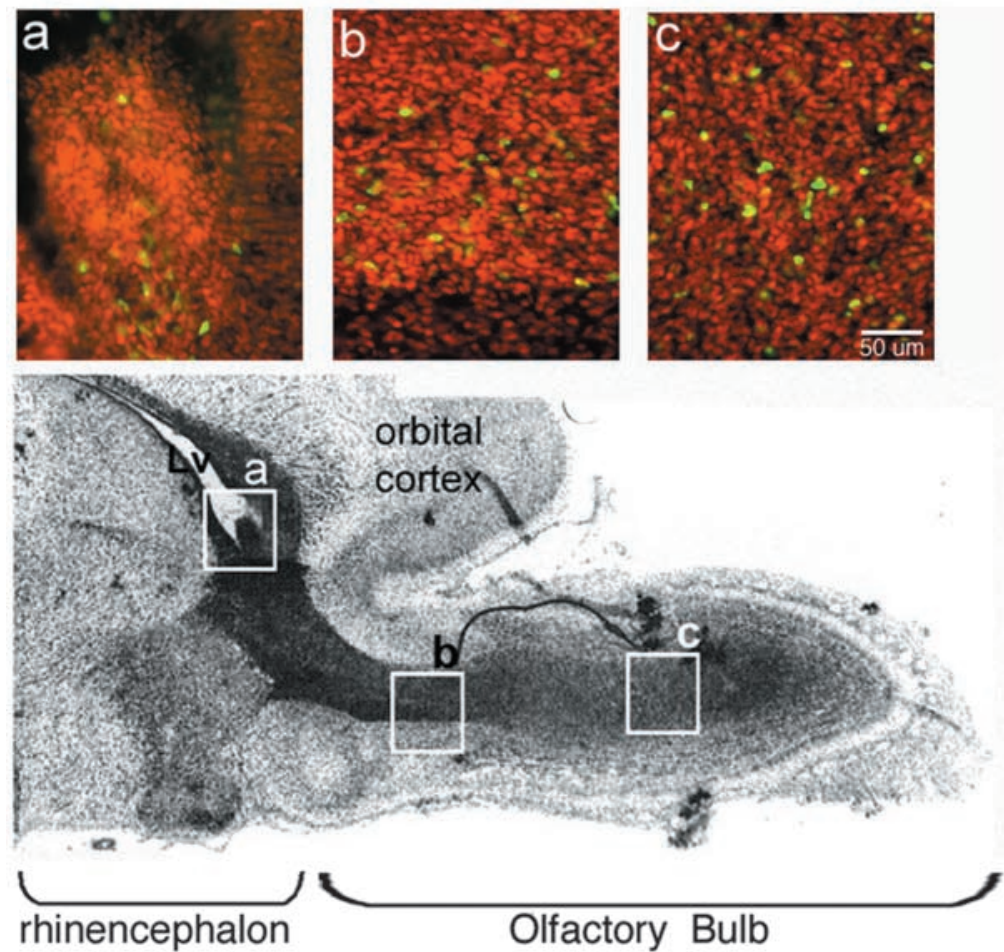


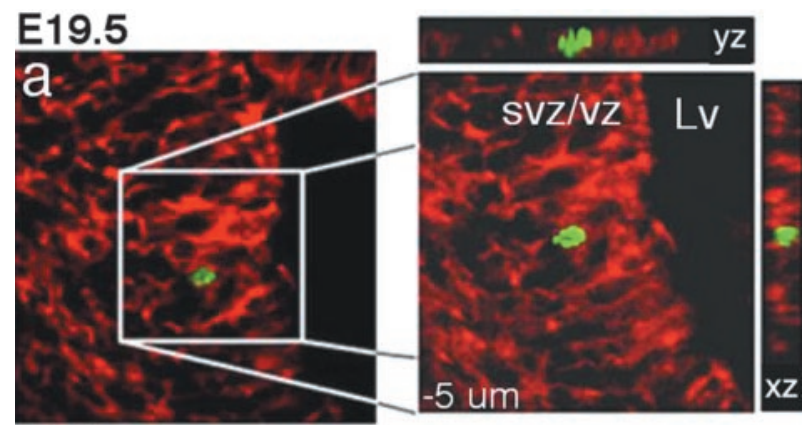

\section{E21.5}

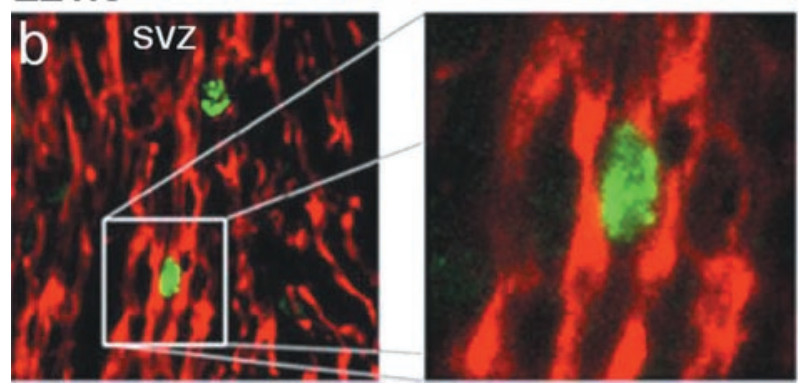

Figure 7. MSCs confined to the cortical germinal zones express nestin 4 and $6 \mathrm{~d}$ after transplantation. $a$, Donor MSCs (BrdU ${ }^{+}$, green) in cortical germinal zones continue to express nestin (red) $4 \mathrm{~d}$ (E19.5) after intraventricular infusion. Z-Series confocal reconstructions of a single optical section show cellular colocalization of nuclear BrdU (green) and cystoplasmic nestin (red) in corresponding $y z$ and $x z$ orthogonal planes. Lv, Lateral ventricle. $b$, Nestin expression (red) by donor MSCs (green) at E21.5 suggests appropriate maintenance of precursor characteristics in cells retained in the SVZ.

\section{E19.5}

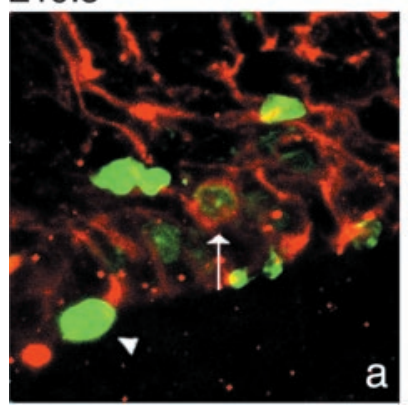

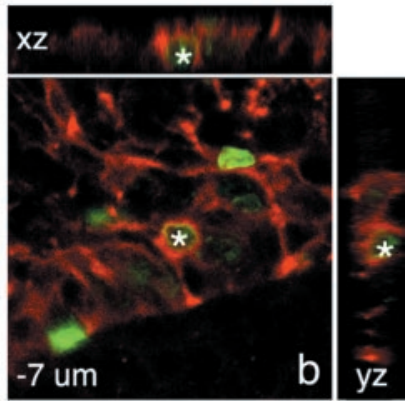

Figure 8. Subsets of MSCs express the astrocytic marker GFAP. a, Populations of donor MSCS (BrdU ${ }^{+}$, green) in basal ganglion (arrow) express GFAP (red), whereas other donor cells are GFAP negative (arrowhead) at E19.5. b, Confocal imaging demonstrates a rim of GFAP-positive cytoplasm surrounding the BrdU-labeled nucleus of a donor MSC (green, asterisk). Cellular colocalization of BrdU (asterisk) and GFAP in $y z$ and $x z$ orthogonal planes is evident.

ined $\mathrm{BrdU}^{+}$cells for $\mathrm{NeuN}$, a neuron-specific marker expressed in postmitotic cells (Sarnat et al., 1998). Colocalization of BrdU and $\mathrm{NeuN}$ was assessed by confocal microscopy in the frontal cortex and olfactory bulb (see Materials and Methods). In the frontal cortex, virtually all of the $\mathrm{BrdU}^{+}$cells stained for $\mathrm{NeuN}$, and 99, 100, and $97 \%$ of the MSCs were NeuN positive in the three animals, respectively (Table 2, Fig. 13). In the olfactory bulb, 70,83 , and $79 \%$ of the MSCs were $\mathrm{NeuN}^{+}$, respectively (Table 2). In summary, MSCs in widely dispersed areas that differ functionally and anatomically expressed this common neuronal trait.
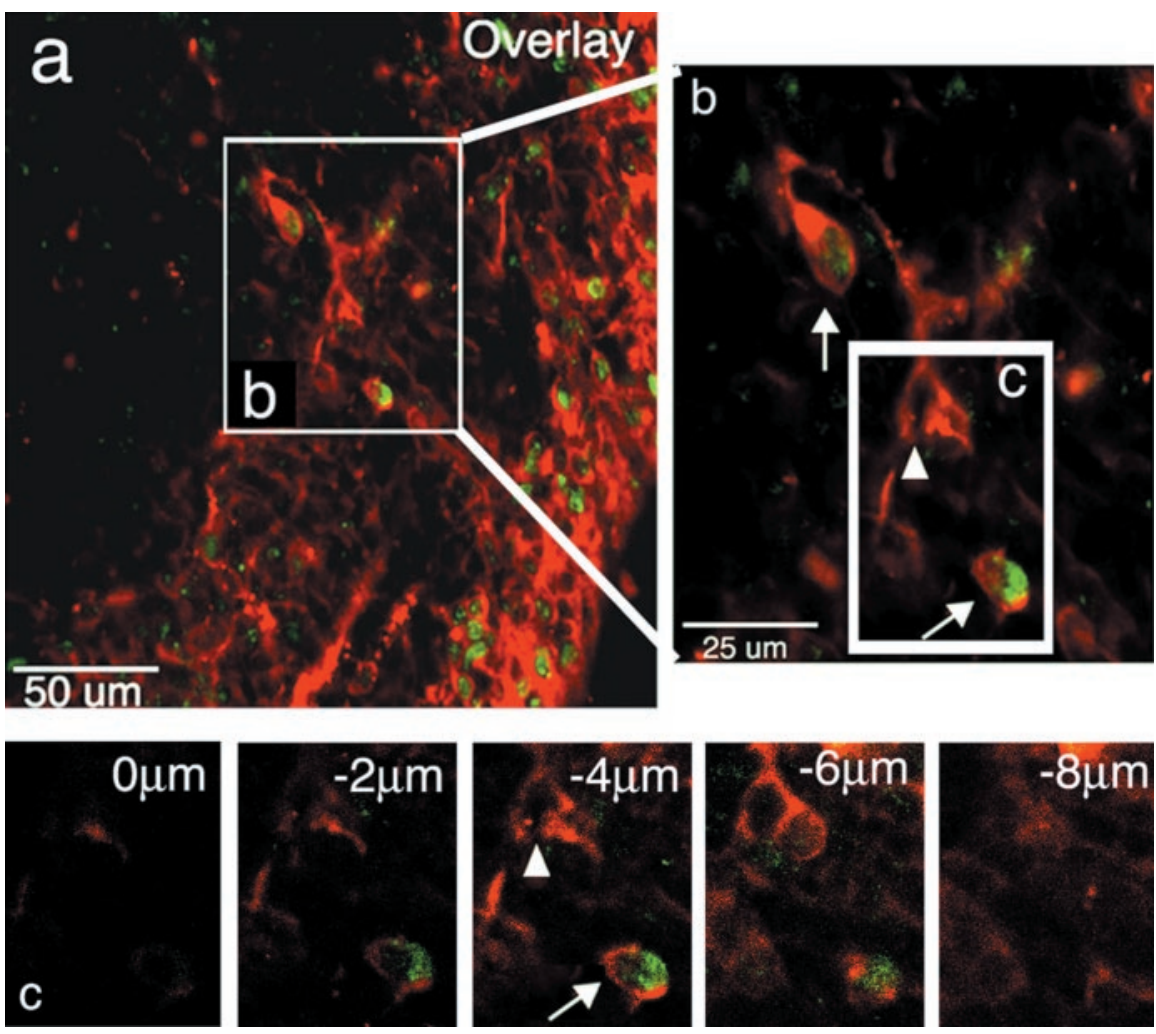

Figure 9. Populations of donor MSCs in the midbrain express $\beta$-III-tubulin at E19.5. $a$, Four days after intraventricular infusion, donor MSCs (BrdU ${ }^{+}$, green) in midbrain regions express the early neuronal protein $\beta$-III-tubulin (red). $b$, High magnification reveals that donor cells (green) expressing $\beta$-III-tubulin (red) exhibit process-bearing neuronal morphologies (arrows) similar to endogenous cells (arrowhead). c, Cellular colocalization of BrdU and $\beta$-III-tubulin was confirmed by confocal analysis of $1-\mu \mathrm{m}$ thick optical sections (arrow).

\section{Discussion \\ Overview}

The present study was designed to determine whether MSCs, which can be differentiated into presumptive neurons in vitro, exhibit neuronal characteristics in the brain in vivo. We chose the neurogenetic embryonic rat brain as a fertile substrate to assess neuronal potentials. In vitro analysis confirmed that the isolated MSCs used in these studies exhibited the ability to differentiate into osteoblasts and adipocytes, indicating the multipotentiality of the starting population. This represents the first demonstration that MSCs engraft, migrate, differentiate, and survive long term in the embryonic brain in vivo.

\section{Ventricular MSCs enter the brain}

Infusion of MSCs into the ventricles at E15.5 resulted in the homogeneous distribution of sheets of cells in the forebrain ventricular system within $24 \mathrm{hr}$, indicating free diffusion within CSF pathways (Fig. 1). Forty-eight hours later, at E17.5, discrete spherical clusters of MSCs were detected throughout periventricular germinal zones (Fig. 2), reminiscent of the pluripotent neurospheres that form in NSC cultures (Reynolds and Weiss, 1992; Reynolds et al., 1992). The MSC spheres observed in vivo may exhibit the multipotentiality of in vitro neurospheres, a contention we are now examining. 
Localization to the SVZ: radial glial and progenitor characteristics

At E17.5, MSCs in the VZ/SVZ expressed the primitive intermediate filament nestin (Fig. 3), characteristic of neuroepithelial precursors (Lendahl et al., 1990). A subset in the cerebellar peduncle/external germinal layer region extended long vimentinpositive fibers (Fig. 4), characteristic of radial glia, now regarded as neuroglial stem cells/precursors (Noctor et al., 2002; Fishell and Kriegstein, 2003; Kriegstein and Gotz, 2003; Weissman et al., 2003). Consistent with this contention, parallel in vitro studies revealed that $>50 \%$ of cultured mouse MSCs expressed the neuroprecursor/radial glial protein RC2 (Fig. 4). Donor cells in the VZ/SVZ did not express the mature neuronal markers tau or MAP2, suggesting that the cells responded appropriately to local cues, assuming a progenitor identity (Chiasson et al., 1999; Laywell et al., 2000; Steindler and Laywell, 2003).

Our observations further suggest that MSCs in the SVZ assumed radial glial functions, including the guidance of migration (Noctor et al., 2002; Fishell and Kriegstein, 2003; Kriegstein and Gotz, 2003; Weissman et al., 2003). The donor cells extended long, vimentin-positive, nestin-positive fibers into the parenchyma (Figs. 3, 4), characteristic of radial glial guidance processes (Noctor et al., 2002; Weissman et al., 2003). Other MSCs with elongated, migratory nuclear morphologies were closely apposed to the spanning fibers (Fig. 5), consistent with migration (Weissman et al., 2003).

\section{Widespread distribution and phenotypic expression of MSCs}

The evidence for extensive MSC migration implies that the cells exhibited another characteristic of normally developing brain neurons, the localization to multiple, distant definitive sites. Abundant donor cells were detected in the neocortex, hippocampi, cerebellar peduncles, colliculi, thalamus, midbrain, forebrain germinal zones, rostral migratory stream, and olfactory bulbs. The MSCs are apparently equipped to follow diverse migratory paths, through different microenvironments to multiple target areas with extensive long-term survival (see below).

The cells expressed different gene products and morphologies in a region-specific manner, apparently exhibiting the plastic ability to respond specifically to different microenvironments. Donor cells confined to the SVZ continued to express neuroepithelial nestin at E19.5 and E21.5. MSCs in the midbrain exhibited multipolar neuronal morphologies and expressed $\beta$-III-tubulin, a neuronal protein, at E17.5. Neocortical cells, on the other hand, expressed mature neuronal tau and MAP2 at E21.5. Donor cells in the pons and basal ganglia exhibited astrocytic morphologies and expressed GFAP. MSC GFAP was not detected in the neocor-
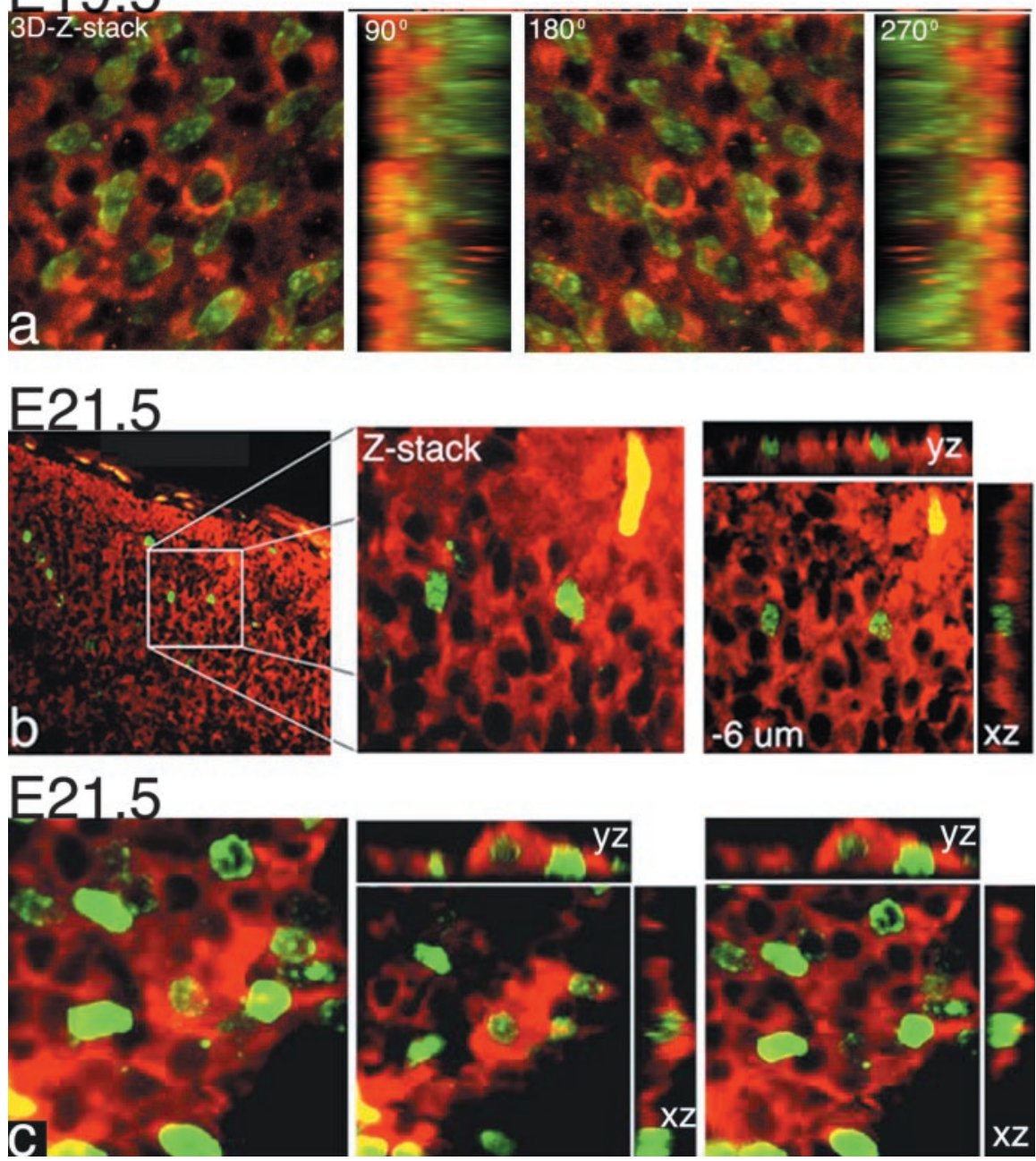

Figure 10. Donor MSCs express tau and MAP2 in a region-specific manner. $a$, Donor MSCs (green) with elongated nuclear morphologies in the white matter at E19.5 do not express the neuronal marker tau (red). Z-Series reconstruction rotated 90, 180,

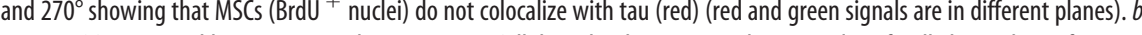
Donor MSCs in cortical layers at E21.5 do express tau. Cellular colocalization was determined confocally by analysis of Z-series reconstructions and single optical sections in corresponding $y z$ and $x z$ orthogonal planes. c, MSCs (green) in the cortical layers express the mature neuronal marker MAP2 (red), confirmed by confocal analysis.

tex at this time. We are presently examining GFAP expression in MSCs transplanted at different ages after different postoperative intervals. Indeed, in previous studies, MSC GFAP has been detected in multiple forebrain regions after transplantation to the mouse at P3 (Kopen et al., 1999).

In addition to expressing mature, generic neuronal traits in an area-specific manner, the MSCs exhibited subregion-specific differentiation. Appropriate subsets of MSCs expressed the specific trait calbindin within the external plexiform layer of the olfactory bulb periglomerular region (Fig. 11), consistent with previous reports of neurons in the mature brain (Halász et al., 1985).

MSCs in non-overlapping periglomerular subregions expressed $\mathrm{TH}$, characteristic of bulb dopaminergic neurons in this subregion (Fig. 12) (Halász et al., 1985).

In summary, donor MSCs exhibited subregion-specific differentiation, consistent with plasticity of this adult population.

\section{Transdifferentiation and cell fusion}

The diverse fates of the MSCs argue against a single intrinsic mechanism governing differentiation. MSCs express heteroge- 

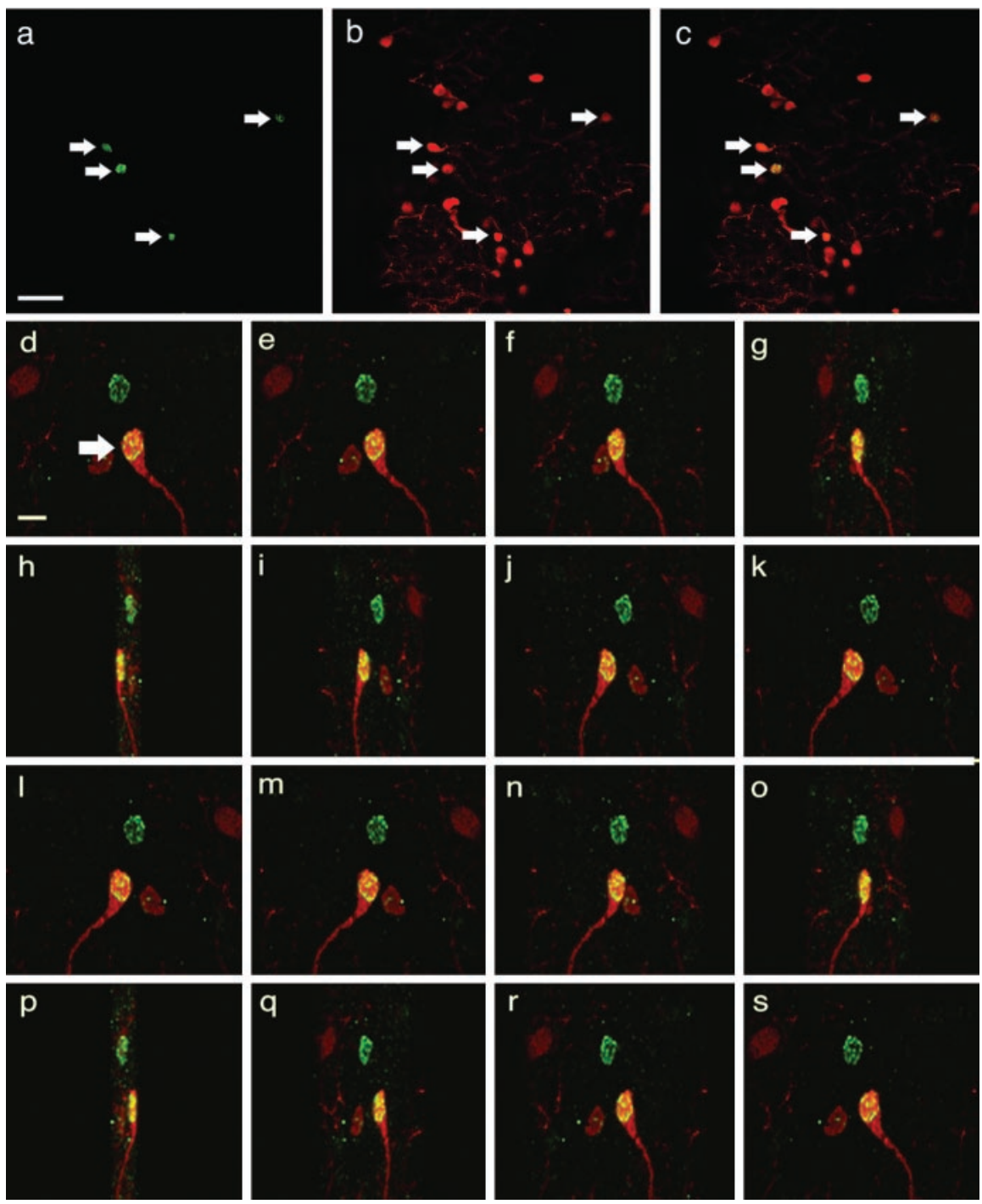

Figure 11. Site-specific expression of calbindin in olfactory bulb MSCs. $a-c$, BrdU-labeled MSCs (green, arrows) within the external plexiform layer of the olfactory bulb express the mature neuronal marker calbindin (red) 1 month postnatally. Scale bar, $50 \mu \mathrm{m} . d$-s, Rotational analysis at $360^{\circ}$ around the $y$-axis of a calbindin-positive, process-bearing, donor MSC (green) in the dorsal periglomerular region of the olfactory bulb (red). Scale bar, $10 \mu \mathrm{m}$.
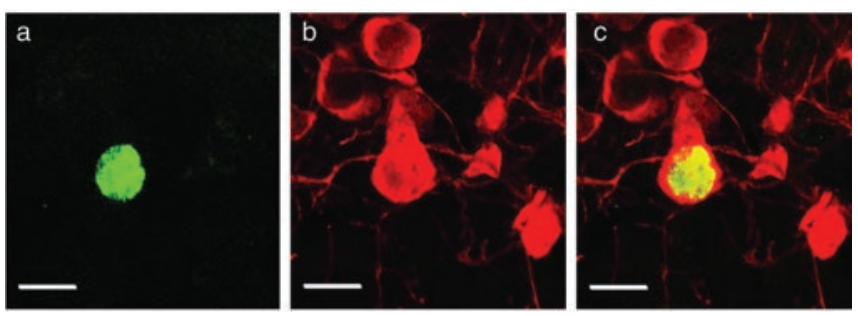

Figure 12. A subpopulation of MSCs within the olfactory bulb express tyrosine hydroxylase. $a-c$, Confocal Z-section demonstrating cellular colocalization of BrdU (green) with tyrosine hydroxylase (red) in the olfactory bulb periglomerular layer at 1 month postnatally. Scale bars, $10 \mu \mathrm{m}$.

neous traits characteristic of (1) radial glia, (2) SVZ progenitors, (3) migratory cells, (4) parenchymal neurons, and (5) glia. MSC fate, consequently, appears to be regulated by multiple influences, presumably including different microenvironments. This may be relevant to several recent reports suggesting that marrow cells can assume different fates through fusion with other cell types. The sheer diversity and widespread distribution of distinct MSC-derived neural types in our studies argues against fusion as a dominant mechanism. Additionally, we never observed multiple nuclei in extensive confocal searches. Furthermore, previous studies have suggested that fusion is a rare event. For example, genetically altered MSCs cultured with embryonic stem (ES) cells yielded only 2-11 hybrid clones per $10^{6}$ marrow cells (Terada et al., 2002), and 1 in $10^{5}$ when genetically altered neural cells were exposed to ES cells (Terada et al., 2002; Ying et al., 2002). In contrast, cultured marrow cells that differentiate into neurons in the absence of other cell types express a variety of neuroglial characters (Sanchez-Ramos et al., 2000; Woodbury et al., 2000; Lee et al., 2003), and marrow multipotent adult progenitor cells differentiate into endothelium, neuroectoderm, and endoderm, as well as mesenchymal derivatives (Jiang et al., 2002a,b, 2003). Furthermore, pancreatic cells differentiate into hepatocytes in vitro and in vivo in the absence of fusion (Krakowski et al., 1999; Shen et al., 2000). In vivo, male donor peripheral blood stem cells transdifferentiate into epidermal, hepatic, and gastric mucosal cells in human females, and the cells contained only one $\mathrm{X}$ and one $\mathrm{Y}$ chromosome, excluding fusion as a mechanism (Korbling et al., 2002). Similarly, differentiation of male marrow cells into mucosal cells throughout the gastrointestinal tract of human female recipients occurred in the absence of evidence of fusion (Okamoto et al., 2002). Nevertheless, in some systems, fusion may play a role: donor hematopoietic stem cells rescued mutant mice with hepatic deficiency by fusing with endogenous hepatic cells (Wang et al., 2002). Moreover, Alvarez-Dolado et al. (2003) recently found that whole bone marrow cells grafted into lethally irradiated mice were capable of fusing with some Purkinje neurons, cardiomyocytes, and hepatocytes. However, the frequency of fusion with Purkinje cells was exceedingly low, 2 of $1.5 \times 10^{6}$ at 2 months and 5 of $1.5 \times$

Table 1. Quantitation of BrdU-labeled cells in the frontal cortex and olfactory bulb

\begin{tabular}{llll}
\hline Subject & $\begin{array}{l}\text { Number of sections } \\
\text { counted }\end{array}$ & $\begin{array}{l}\text { Average nuclear } \\
\text { diameter }(\mu \mathrm{m})\end{array}$ & $\begin{array}{l}\text { Number of BrdU } \\
\text { per section }\end{array}$ \\
\hline FC 1 & 8 & 11 & $501 \pm 88$ \\
FC 2 & 9 & 12 & $226 \pm 97$ \\
FC 3 & 7 & 12 & $118 \pm 22$ \\
OB 1 & 7 & 5 & $239 \pm 32$ \\
OB 2 & 8 & 5 & $222 \pm 33$ \\
OB 3 & 6 & 5 & $49 \pm 9$ \\
\hline
\end{tabular}

Tissue from 1-month-old rats was used for all determinations. For the frontal cortex (FC), $16 \mu \mathrm{m}$ sagittal section extend from the rostral extreme of the lateral ventricle to the frontal pole. Every third section was subjected to morphometry, scoring BrdU-positive cells. For the olfactory bulb (OB), $16 \mu \mathrm{m}$ sections extend from the rostral pole to a limit of $500 \mu \mathrm{m}$ caudally and were scored for BrdU-positive cells. The diameters of 50 nuclei were determined from three sections per animal for cortex and olfactory bulb to correct for double counting (Abercrombie correction; for details, see Materials and Methods). Nuclear diameters are expressed as an average for each animal. (ell number is expressed as mean \pm SEM 
$10^{6}$ at 4 months. In contrast, we detected thousands of MSCs throughout the brain. This provocative work, however, may not be directly relevant to the present study. First, their experiments demonstrated that hematopoietic marrow cells fuse in vivo. However, our studies were performed with marrow stromal cells, an entirely different population. Second, they used irradiated adult mouse hosts, whereas we examined normal embryonic rats. Finally, we found presumptive neurons in virtually all parenchymal and germinal areas, whereas they only described fusion in rare Purkinje cells. In summary, the relevance of their important work with hematopoietic cells grafted to lethally irradiated mice, yielding fusion of undetermined frequency, must be documented in additional studies. Furthermore, in a counter example, transplanted marrow cells differentiated into human buccal mucosa in vivo, of which $12.7 \%$ were donor derived, although only $0.1 \%$ exhibited evidence of fusion (Tran et al., 2003). It is particularly difficult to envision mechanisms through which cellular fusion could generate the multiplicity of cell types from MSCs in the present study. Consideration of the quantitative aspects of the present results emphasizes this point.

\section{Long-term survival of transplanted cells: quantitative analysis}

MSC-derived cells exhibited widespread survival at 1 and 2 postnatal months, the longest times examined. Cells were abundant in the germinal VZ/SVZ and RMS, as well as widespread parenchymal areas. Widespread survival indicates adaptation of the cells to diverse brain niches that differ anatomically, physiologically, and functionally, substantiating plasticity of the MSCs in vivo.

Morphometry was performed at 1 month to estimate long-term survival and plasticity. MSCs were so densely packed in the VZ/SVZ that resolution of individuals and accurate counting were not possible. We chose the frontal cortex and olfactory bulb as representative of functionally critical parenchymal and germinal areas that require migration. Although sections from both areas exhibited abundant $\mathrm{BrdU}^{+}$cells, numbers varied from animal to animal, presumably reflecting variable access from different ventricular locations, differences in migratory pathways, altered mitotic rates, and variable survival itself. In the frontal cortex, there were 4792,2152 , and 1124 donor cells $/ \mathrm{mm}^{3}$ in individual rats. Clearly, thousands of cells survive into young adulthood.

Abundant cells were also detected in the olfactory bulb. In the 1 month bulb, there were $10,864,10,091$, and $2229 \mathrm{MSCs} / \mathrm{mm}^{3}$ in individual rats. In summary, long-term survival of donor cells in diverse, developmentally changing brain environments indicates the viability and plasticity of MSC derivatives.

To begin identifying the phenotype of the MSCs at 1 month, we stained sections for NeuN, a postmitotic, neuron-specific marker (Sarnat et al., 1998). Approximately $99 \%$ of the frontal cortex MSCs expressed NeuN, whereas 70, 83, and 79\% were $\mathrm{NeuN}^{+}$in the olfactory bulbs of three separate animals. It should be reiterated that donor cells in the SVZ did not express NeuN at this age, indicating that expression is region appropriate and not a function of intrinsic MSC “aging." We conclude that transindicated by arrows.
Table 2. Colocalization of NeuN and BrdU in the frontal cortex and olfactory bulb

\begin{tabular}{lllr}
\hline Subject & $\begin{array}{l}\text { Total number of BrdU } \\
\text { cells counted }\end{array}$ & $\begin{array}{l}\text { Number of BrdU } \\
\text { cells counted }\end{array}$ & Percentage \\
\hline FC 1 & 194 & 193 & $99 \%$ \\
FC 2 & 187 & 187 & $100 \%$ \\
FC 3 & 183 & 178 & $97 \%$ \\
OB 1 & 266 & 185 & $70 \%$ \\
OB 2 & 101 & 84 & $83 \%$ \\
OB 3 & 140 & 111 & $79 \%$ \\
\hline
\end{tabular}

Tissue from 1-month-old rats was used in all determinations. To define NeuN expression in BrdU-positive cells, confocal analysis was performed on sections of each of the three animals, examining a minimum of 150 labeled cells for the frontal cortex and 100 cells for the olfactory bulb (for details, see Materials and Methods). The right column represents the percentage of $\mathrm{BrdU}^{+}$cells that exhibited NeuN positivity for each individual animal.
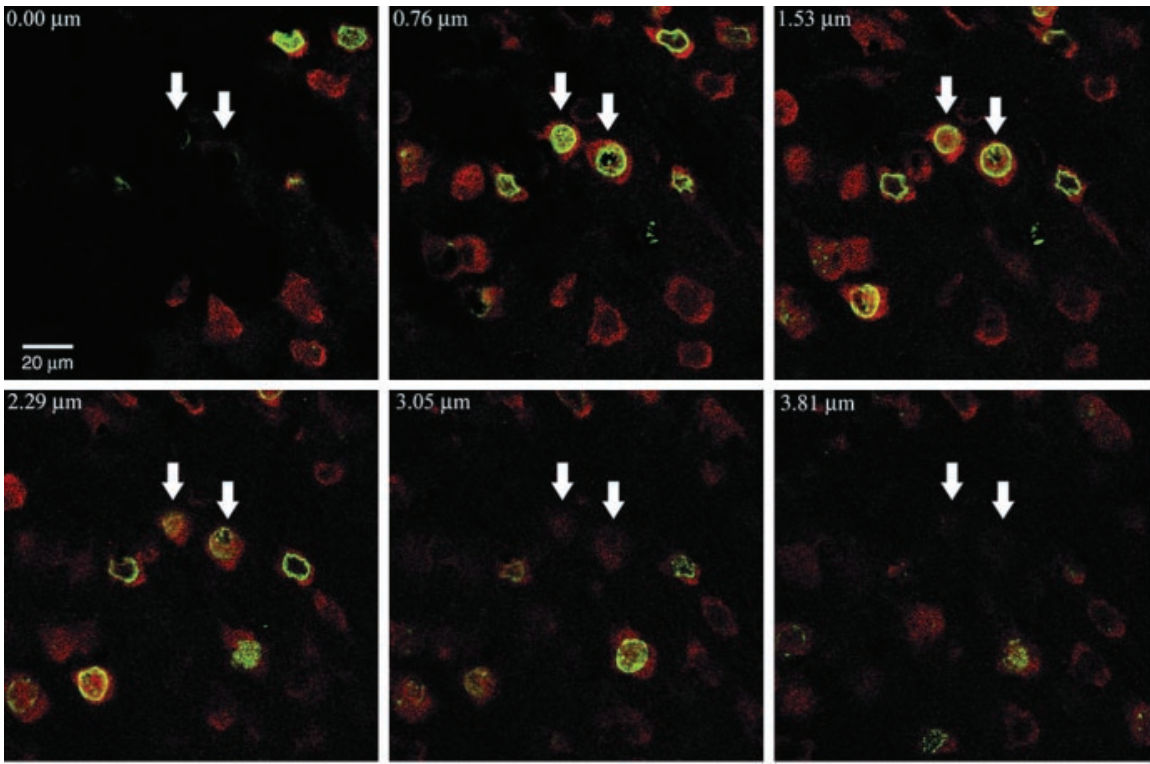

Figure 13. MSCs in the frontal cortex express the postmitotic neuronal marker NeuN. Confocal analysis demonstrates that the majority of donor MSCs (green) in the frontal cortex expresses NeuN (red), a marker of mature neurons. Representative cells are

planted MSCs exhibit long-term, persistent plasticity in vivo, extending at least into young adulthood.

\section{References}

Alvarez-Dolado M, Pardal R, Garcia-Verdugo JM, Fike JR, Lee HO, Pfeffer K, Lois C, Morrison SJ, Alvarez-Buylla A (2003) Fusion of bone-marrowderived cells with Purkinje neurons, cardiomyocytes and hepatocytes. Nature 425:968-973.

Azizi SA, Stokes D, Augelli BJ, DiGirolamo C, Prockop DJ (1998) Engraftment and migration of human bone marrow stromal cells implanted in the brains of albino rats-similarities to astrocyte grafts. Proc Natl Acad Sci USA 95:3908-3913.

Bjornson CR, Rietze RL, Reynolds BA, Magli MC, Vescovi AL (1999) Turning brain into blood: a hematopoietic fate adopted by adult neural stem cells in vivo. Science 283:534-537.

Brazelton TR, Rossi FMV, Keshet GI, Blau HM (2000) From marrow to brain: expression of neuronal phenotypes in adult mice. Science 290:1775-1779.

Castro RF, Jackson KA, Goodell MA, Robertson CS, Liu H, Shine HD (2002) Failure of bone marrow cells to transdifferentiate into neural cells in vivo. Science 297:1299.

Chiasson BJ, Tropepe V, Morshead CM, van der Kooy D (1999) Adult mammalian forebrain ependymal and subependymal cells demonstrate proliferative potential, but only subependymal cells have neural stem cell characteristics. J Neurosci 19:4462-4471.

Doetsch F, Caille I, Lim DA, Garvia-Verdugo JM, Alvarez-Buylla A (1999) Subventricular zone astrocytes are neural stem cells in the adult mammalian brain. Cell 97:703-716. 
Fishell G, Kriegstein AR (2003) Neurons from radial glia: the consequences of asymmetric inheritance. Curr Opin Neurobiol 13:34-41.

Galli R, Borello U, Gritti A, Minasi MG, Bjornson C, Coletta M, Mora M, DeAngelis MGC, Fiocco R, Cossu G, Vescovi AL (2000) Skeletal myogenic potential of human and mouse neural stem cells. Nat Neurosci 3:986-991.

Halász N, Ljungdahl Å, Hökfelt T, Johansson O, Goldstein M, Park D, Biberfeld P (1977) Transmitter histochemistry of the rat olfactory bulb. I. Immunohistochemical localization of monoamine synthesizing enzymes. Support for intrabulbar, periglomerular dopamine neurons. Brain Res 126:455-474.

Halász N, Hökfelt T, Norman AW, Goldstein M (1985) Tyrosine hydroxylase and $28 \mathrm{~K}$-vitamin $\mathrm{D}$-dependent calcium binding protein are localized in different subpopulations of periglomerular cells of the rat olfactory bulb. Neurosci Lett 61:103-107.

Jiang Y, Jahagirdar BN, Reinhardt RL, Schwartz RE, Keene CD, OrtizGonzalez XR, Reyes M, Lenvik T, Lund T, Blackstad M, Jingbo D, Aldrich S, Lisberg A, Low WC, Largaespada DA, Verfaillie CM (2002a) Pluripotency of mesenchymal stem cells derived from adult marrow. Nature 418:41-49.

Jiang Y, Vaessen B, Lenvik T, Blackstad M, Reyes M, Verfaillie CM (2002b) Multipotent progenitor cells can be isolated from postnatal murine bone marrow, muscle, and brain. Exp Hematol 30:896-904.

Jiang Y, Henderson D, Blackstad M, Chen A, Miller RF, Verfaillie CM (2003) Neuroectodermal differentiation from mouse multipotent adult progenitor cells. Proc Natl Acad Sci USA 100:11854-11860.

Kopen GC, Prockop DJ, Phinney DG (1999) Marrow stromal cells migrate throughout forebrain and cerebellum, and they differentiate into astrocytes after injection into neonatal mouse brains. Proc Natl Acad Sci USA 96:10711-10716.

Korbling M, Katz RL, Khanna A, Ruifrok AC, Rondon G, Albitar M, Champlin RE, Estrov Z (2002) Hepatocytes and epithelial cells of donor origin in recipients of peripheral-blood stem cells. N Engl J Med 346:738-746.

Krakowski ML, Kritzik MR, Jone EM, Krahl T, Leem J, Arnush M, Du D, Sarvetnick N (1999) Pancreatic expression of keratinocytes growth factor leads to differentiation of islet hepatocytes and proliferation of duct cells. Am J Pathol 154:683-691.

Kramer BM, Van der Zee CE, Hagg T (1999) P75 nerve growth factor receptor is important for retrograde transport of neurotrophins in adult cholinergic basal forebrain neurons. Neuroscience 94:1163-1172.

Krause DS, Theise ND, Collector MI, Henegariu O, Hwang S, Gardner R, Neutzel S, Sharkis SJ (2001) Multi-organ, multi-lineage engraftment by a single bone marrow-derived stem cell. Cell 105:369-377.

Kriegstein AR, Gotz M (2003) Radial glia diversity: a matter of cell fate. Glia 43:37-43.

Laywell ED, Rakic P, Kukekov VG, Holland E, Steindler DA (2000) Identification of a multipotent astrocytic stem cell in the immature and adult mouse brain. Proc Natl Acad Sci USA 97:13883-13888.

Lee J, Elkahloun AG, Messina SA, Ferrari N, Xi D, Smith CL, Cooper Jr R, Albert PS, Fine HA (2003) Cellular and genetic characterization of human adult bone marrow-derived neural stem-like cells: a potential antiglioma cellular vector. Cancer Res 63:8877-8889.

Lee JY, Qu-Petersen Z, Cao B, Kimura S, Jankowski R, Cummins J, Usas A, Gates C, Robbins P, Wernig A, Huard J (2000) Clonal isolation of muscle-derived cells capable of enhancing muscle regeneration and bone healing. J Cell Biol 150:1085-1100.

Lendahl U, Zimmerman LB, McKay RDG (1990) CNS stem cells express a new class of intermediate filament protein. Cell 60:585-595.

Lu D, Mahmood A, Wang L, Li Y, Lu M, Chopp M (2001) Adult bone marrow stromal cells administered intravenously to rats after traumatic brain injury migrate into brain and improve neurological outcome. NeuroReport 12:559-563.

Mezey E, Chandross K, Harta G, Maki R, McKercher S (2000) Turning blood into brain: cells bearing neuronal antigens generated in vivo from bone marrow. Science 290:1779-1782.

Morshead CM, Reynolds BA, Craig CG, McBurney MW, Staines WA, Morassutti D, Weiss S, van der Kooy D (1994) Neural stem cells in the adult mammalian forebrain: a relatively quiescent subpopulation of subependymal cells. Neuron 13:1071-1082.

Noctor DC, Flint AC, Weissman TA, Wong WS, Clinton BK, Kriegstein AR (2002) Dividing precursor cells of the embryonic cortical ventricular zone have morphological and molecular characteristics of radial glia. J Neurosci 22:3161-3173.

Okamoto R, Yajima T, Yamazaki M, Kani T, Mukai M, Okamoto S, Ikeda Y, Hibi T, Inazawa J, Watanabe M (2002) Damaged epithelia regenerated by bone marrow-derived cells in the human gastrointestinal tract. Nat Med 8:1011-1017.

Prockop DJ (1997) Marrow stromal cells as stem cells for non-hematopoietic tissues. Science 276:71-74.

Reynolds BA, Weiss S (1992) Generation of neurons and astrocytes from isolated cells of the adult mammalian central nervous system. Science 255:1707-1710.

Reynolds BA, Tetzlaff E, Weiss S (1992) A multipotent EGF-responsive striatal embryonic progenitor cell produces neurons and astrocytes. J Neurosci 12:4565-4574.

Sanchez-Ramos J, Song S, Cardozo-Perez F, Hazzi C, Stedeford T, Willing A, Freeman TB, Saporta S, Janssen W, Patel N, Cooper DR, Sanberg PR (2000) Adult bone marrow stromal cells differentiate into neural cells in vitro. Exp Neurol 164:247-256.

Sarnat HB, Nochlin D, Born DE (1998) Neuronal nuclear antigen (NeuN): a marker of neuronal maturation in early human fetal nervous system. Brain Res 20:88-94.

Sasaki M, Hanmou O, Akiyama Y, Uede T, Hashi K, Kocsis JD (2001) Transplantation of an acutely isolated bone marrow fraction repairs demyelinated adult rat spinal cord axons. Glia 35:26-34.

Shen CN, Slack JM, Tosh D (2000) Molecular basis of transdifferentiation of pancreas to liver. Nat Cell Biol 2:879-887.

Steindler DA, Laywell ED (2003) Astrocytes as stem cells: nomenclature, phenotype, and translation. Glia 43:62-69.

Terada N, Hamazaki T, Oka M, Hoki M, Mastalertz DM, Nakano Y, Meyer EM, Morel L, Petersen BE, Scott EW (2002) Bone marrow cells adopt the phenotype of other cells by spontaneous cell fusion. Nature 416:542-545.

Theise ND, Saxena R, Portmann BC, Thung SN, Yee H, Chiriboga L, Kumar A, Crawford JM (1999) The canals of hering and hepatic stem cells in humans. Hepatology 30:1425-1433.

Toma JG, Akhavan M, Fernandes KJL, Barnabe-Heider F, Sadikot A, Kaplan DR, Miller FD (2001) Isolation of multipotent adult stem cells from the dermis of mammalian skin. Nat Cell Biol 3:778-784.

Tran SD, Pillemer SR, Dutra A, Barrett AJ, Brownstein MJ, Key S, Pak E, Leakan RA, Kingman A, Yamada KM, Baum BJ, Mezey E (2003) Differentiation of human bone marrow-derived cells into buccal epithelial cells in vivo: a molecular analytical study. Lancet 361:1084-1088.

Wang X, Montini E, Al-Dhalimy M, Lagasse E, Finegold M, Grompe M (2002) Kinetics of liver repopulation after bone marrow transplantation. Am J Pathol 161:565-574.

Weissman T, Noctor SC, Clinton BK, Honig LS, Kriegstein AR (2003) Neurogenic radial glial cells in reptile, rodent and human: from mitosis to migration. Cereb Cortex 13:550-559.

Woodbury D, Schwarz EJ, Prockop DJ, Black IB (2000) Adult rat and human bone marrow stromal cells differentiate into neurons. J Neurosci Res 61:364-370.

Woodbury D, Reynolds K, Black IB (2002) Adult bone marrow stromal cells express germline, ectodermal, endodermal, and mesodermal genes prior to neurogenesis. J Neurosci Res 96:908-917.

Ying QL, Nichols J, Evans EP, Smith AG (2002) Changing potency by spontaneous fusion. Nature 416:545-548. 